A LITERATURE REVIEW OF ROLE OF OBESITY IN ADULT HEALTH WITH REFERENCE TO AFRICA

\title{
Lokuruka $\mathrm{MNI}^{1} *$
}

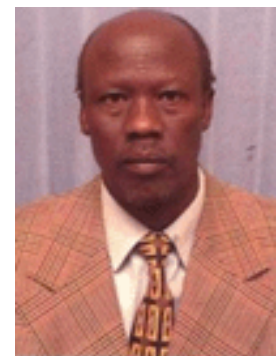

Michael Lokuruka

*Corresponding author email: mlokuruka@gmail.com

${ }^{1}$ Associate Professor of Food Science, Department of Food Science and Nutrition, Karatina University College, P.O. Box 1957-10101, Karatina, Kenya. 


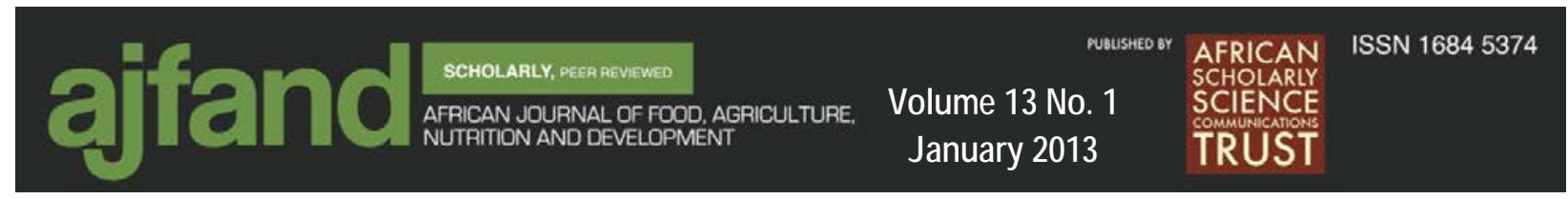

\section{ABSTRACT}

Although obesity is a global epidemic that affects every socio-economic class, little is available in the literature on the status of the syndrome in Africa. This literature review was therefore written in order to highlight the causes, effects and potential mitigation measures of the syndrome with particular interest on the status of the condition in Africa. Obesity results from an incorrect energy balance leading to an increased store of energy, mainly as fat. The major factors that contribute to obesity include over-nutrition, physical inactivity, change of dietary habits, modernization, consumption of high fat, high carbohydrate foods, urbanization and in a minority of patients a physical condition or metabolic disturbance. Body mass index (BMI) is currently being used by competent authorities as an index of obesity. BMI differentiates classes of obesity, with class I, II and III being identified with BMI of $\geq 30$ but $<35, \geq 35$ but $<40$, and $\geq 40$, respectively. A BMI of $18.5-25$ is regarded as normal. However, it is sometimes difficult to differentiate obesity due to excess fat deposition and that due to muscle atrophy. Also, current procedures for estimating body fat percentage are not as accurate as they should and often give different results. Despite women tending to be more obese than men, they are less prone to hypertension, heart disease and type 2 diabetes than men before they reach menopause due to their fat deposition being predominantly sub-cutaneous rather than abdominal. In 2010, the WHO estimated that about 1.4 billion adults were overweight and obese, but 300-400 million were obese. The defining metabolic changes in obesity are decreased glucose tolerance, decreased sensitivity to insulin, hyperinsulinemia and reduced life expectancy. Obesity can be treated by restricting food intake and engaging in regular physical exercises. Other measures include the use of anorectic drugs and various forms of jejunoileostomy. Obesity is a controllable behavioural disorder, with regular exercise and sensible eating being the best ways to regulate body fat percentage and maintain a healthy body weight. As it is difficult to treat obesity, efforts should be directed towards prevention in order to keep it in check.

Keywords: Obesity, global situation, Africa, mitigation 


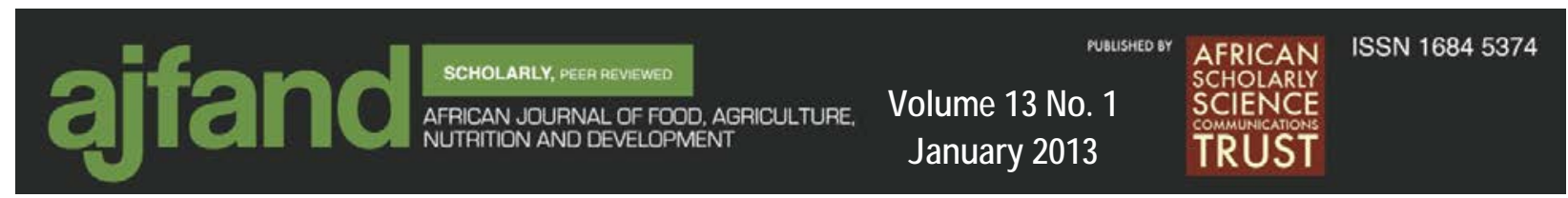

\section{INTRODUCTION - Defining and Assessing Obesity}

Obesity is a state in which an excess of fat has accumulated in the body. Assessment is usually done by weighing the patient and relating weight to height. The weight (W) in kilograms over height $(\mathrm{H})$ in meters ${ }^{2}\left(\mathrm{H}^{2}\right)$ gives an index commonly referred to as the body mass index (BMI). The measure of BMI is used to differentiate classes of obesity in patients. Class I, II and III obesity are identified with BMI of $\geq 30$ but $<35$, $\geq 35$ but $<40$, and $\geq 40$, respectively [1]. A person with a BMI $<25$ is not obese according to current classification [2]. However, the above definition of obesity does not distinguish between overweight due to obesity and muscle hypertrophy. Also, although obesity is a simple index of weight-for-height that is commonly used to classify overweight and obesity in adults, it may not correspond to the same degree of fatness in different individuals [3]. Despite BMI being a rough guide, it is nevertheless the most useful population-level measure of overweight and obesity as it is the same for both sexes and for all ages of adults. However, one study found that BMI underestimates obesity especially in women with high leptin levels ( $>30 \mathrm{ng} / \mathrm{mL}$ ), although the accuracy can be improved by using the revised leptin levels to estimate body fat percentage when dual-energy X-ray absorptiometry (DEXA) is available [4]. Obesity and overweight are the fifth leading causes of global deaths [3]. The US National Institutes of Health regards BMI of 25.0-29.9 as overweight, and strongly discourages having a BMI less than 18.5 (underweight) [5]. It defines obesity as BMI $>30$, and overweight in women being $27.3 \%$ or more than the normal BMI for their height and weight, while for men, it is $27.8 \%$ or more than the normal BMI for men. Computed tomography (CT) scans and hormonal blood tests seem to give more accurate estimates of visceral fat than waistline measurements [1]. However, one study found that CT scanners may be imprecise for visceral fat estimation unless a flexible attenuation range is used for determining abdominal fat distribution [6]. Also, another study found that anthropometric measurements and visceral fat tissue measurements such as ultrasonography and bioimpedance analysis (BIA) exhibit differences with respect to compliance with $\mathrm{CT}$ results in visceral fat tissue measurements by gender and BMI [7]. These observations point to the need to find more accurate methods and procedures for estimating obesity in individuals. Good comparisons between methods for measurement of obesity are also needed. Some recent methods which are being tried include improved CT radiology, dual energy Xray absorptiometry (DEXA), bioimpedance analysis (BIA) and their combinations [6, 8].

\section{GLOBAL TRENDS OF OBESITY}

It was not until the 20th century that the WHO finally recognized obesity as a global epidemic. As of 2010, the WHO estimated that at about 300-400 million adults were obese, while 1 billion were overweight, with higher rates for both conditions among women than men [9]. The rate of obesity also increases with age up to 50 or 60 years. Once considered a problem of rich countries, obesity rates are increasing worldwide, with developing countries experiencing unprecedented increases. A new word describing the global nature of the epidemic has been coined-"globesity". The increases in obesity are felt most dramatically in urban settings. The only remaining 


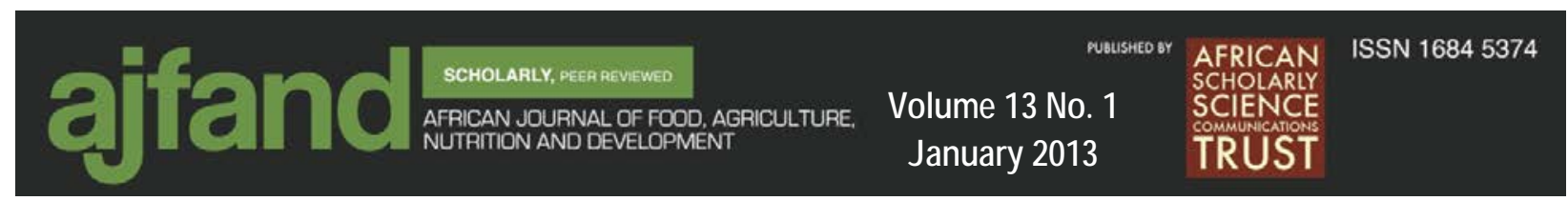

region where obesity is not common is sub-Saharan Africa [9], but there is an upward trend.

A WHO/PAHO dietary survey revealed that as Latin American countries emerge from poverty, there is an increasing trend in obesity, especially in urban settings [10]. In contrast, in the middle income countries of the region, obesity is seen to decrease as incomes rise, especially among women. The increased obesity rates are explained by dietary changes and increased inactivity, especially among low-income groups who improve their incomes but predominantly buy high fat, high carbohydrate and energy-dense foods [10]. The increased intake of these foods is detrimental to the intake of grains, fruits and vegetables in the same population groups. Most of these region's aboriginal populations seem to have changed their dietary habits and physical activity to fit industrialized country models; they indulge in Western fast foods, and lead sedentary and physically inactive lifestyles. With this trend, the rates of obesity, insulin resistance and type 2 diabetes are observed to be on the rise [10]. The rates were high among women, especially those with little schooling, and occurred more frequently in poorer households [11]. The authors attributed the rise in obesity to infant and foetal nutritional malnutrition, inadequate or lack of education and socioeconomic conditions, dietary changes towards energy dense foods and physical inactivity.

The WHO points out that under-nutrition in the foetal stage and in infancy predisposes one to obesity in older age where socio-economic conditions favour it [9]. Although childhood obesity is as common in Russia as in the US, Russians seem to lose weight as they approach adulthood [12]. In a nationally representative study of Russian adults, aged between 19 and 55 years in the first 8 years of the Russian Federation's transition to a market economy, it was found that overweight remained fairly stable over the period at 50\%, while obesity increased from 13.3 to $16 \%$ in the adult population [12].

The Food Standards Agency of the UK gave published data for obesity (\%) (females vs. males) in some countries from 1999-2000 as follows: the Russian Federation (25 vs. 10), Mexico (25 vs. 15), Argentina (25 vs. 28), France (7 vs. 8), the UK (24 vs. 21), Germany (19 vs. 17), Italy (9.9 vs. 9.5), Spain (15 vs. 12) [13]. However, these estimates may have changed over the period after the date.

The WHO estimated that adult BMI of 22-23 were prevalent in most countries of Africa and Asia, while BMI of 25-27 were prevalent in North America, Europe and parts of Latin America, North Africa and some Pacific Island countries [14]. It estimated that obesity rates vary from below 5\% in China, Japan and certain African countries to over $75 \%$ in urban Samoa. However, in China, rates were as high as $20 \%$ in some cities, similar to cities in the developed world [14]. The rates of the epidemic in the UK are some of the highest in Europe [14]. 


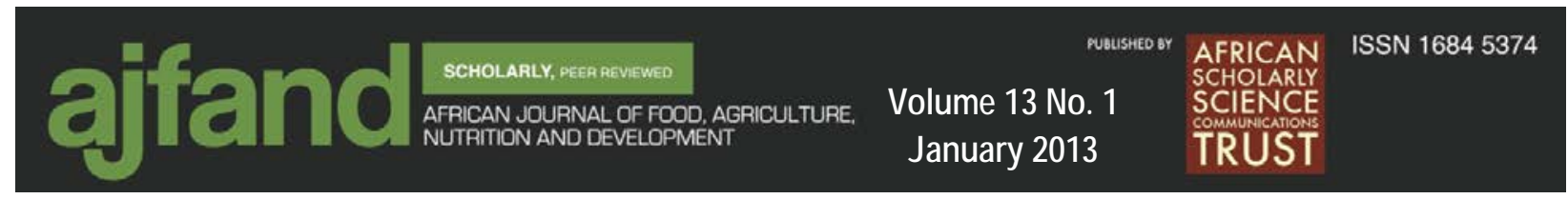

\section{Regional levels of obesity}

The US has the highest rates of obesity among developed countries (32\%), in the adult population [14]. The rates vary with gender and ethnicity. It is higher in women than men (35 versus 33\%), similar to other regions of the world. In the US, the scourge is higher among African-Americans than other races [15]. In Canada, the aboriginals tend to be more obese than the Caucasian groups [15]. Due to the dramatic rise in Class III obesity, more than $30 \%$ of annual deaths in the US are reported to be associated with obesity related ill-health complications [15].

In a sample of 7786 women aged 19-95 years old in South Africa, black women had the highest prevalence of overweight and obesity (58.5\%), followed by women of mixed ancestry (52\%), white women (49.2\%) and Indian women (42.8\%) [16]. Urban women had higher BMI than their rural counterparts and in both groups, BMI increased with age. Central obesity (defined by cut-off points for waist to hip ratio of 0.85 for women and 1.0 for men) was higher among urban African women (42\%) and was most prevalent in African women and among women of mixed race [16]. The overall prevalence of obesity and overweight in South Africa is high, with $29 \%$ of men and $56 \%$ of women being classified as overweight or obese. This is higher than reported in other African countries, particularly among women, since 30\% of South African women aged between 30 and 59 were reported obese [16]. The other African region where obesity rates are as high as in South Africa is North Africa [14].

In a cross-sectional study among the Luo, Maasai and Kamba, in rural and urban Kenya, among 1430 individuals (58.3\% females), aged 17-68 years, abdominal visceral and subcutaneous fat, arm fat area (AFA), and waist circumference increased with age and were highest among the Maasai and in urban populations [17]. AFA increased only with increasing age among males. The prevalence of overweight (BMI $\geq 25$ ) and obesity (BMI $\geq 30$ ) was higher in Kenyan urban compared to the rural populations studied (39.8\% vs. 15.8\%) [17]. Abdominal visceral and subcutaneous fat thickness was highest with urban residency. In this Kenyan study, a high prevalence of overweight and obesity was found with the highest fat accumulation among the Maasai [17]. The mean Kenya national prevalence rate was estimated as 13\% in 2004 [18].

In Asia, India, China, Indonesia, Japan and Bangladesh are listed among the WHO's 10 countries with the greatest prevalence of obesity. In India, morbid obesity in the $21^{\text {st }}$ century has reached $5 \%$ of the country's population, while in Chinese cities, $12 \%$ of adults and $8 \%$ of children were reported obese [14].

\section{The obesity outlook in Africa}

In West Africa, the rate of obesity is about $10 \%$ [14]. It is 3x higher among women than men. In parts of West Africa, the rates have more than doubled in the last 15 years [14]. In South Africa one in 3 men and one in 2 women are either overweight or obese [16]. These South African statistics are close to the figures for the US. In Morocco, the rate of obesity is estimated to be $40 \%$ in the general population, while it is estimated to be about $12 \%$ in Kenya [17]. However, the most worrying trend is childhood obesity among well-fed and inactive school age children in Kenya and 


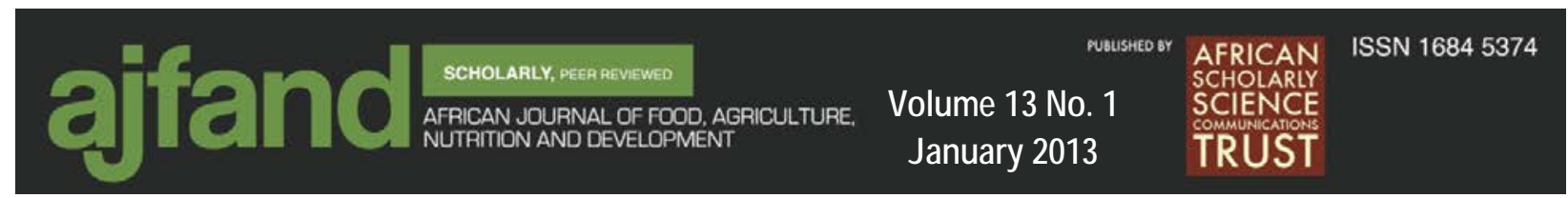

other developing countries. In Nigeria, it is estimated that about $6-8 \%$ of the population is obese [19]. It is opined that the increasing consumption of processed and high fat fast foods, frequent snacking while watching movies and lack of regular exercise are contributing to the rise of the scourge. Zizza and others reported that between 1978 and 1996, there was a significant proportion of young adults snacking, representing a case for concern worldwide [20]. The lack of space for sports grounds and facilities in African cities is contributing to the rise in rates of the epidemic in urban areas. The habit of families sitting for long hours watching TV, videos and children playing video games for long, is also likely to contribute to the rising rates of obesity and overweight among affluent and middle class urban dwellers. The prevalence rates of obesity in select African countries was 13, 14 and 15\% in Sudan, Egypt and Libya (North Africa), 15, 10 and 9\% in Ghana, Senegal and Niger (West Africa), and 13, 12 and 14\%, respectively, in Kenya, Uganda and Tanzania in East Africa [18].

\section{CAUSES AND AETIOLOGY OF OBESITY}

Obesity is the result of an incorrect energy balance leading to an increased store of energy, mainly as fat. Overweight and obesity can impair health. The two types of fat depositions are sub-cutaneous and visceral. High visceral fat deposition is normally associated with elevated plasma low-density lipoprotein (LDL) cholesterol, which in turn may lead to hypertension, diabetes, heart disease and stroke [21]. Although women tend to be more obese than men, their fat type is predominantly the subcutaneous than the abdominal type before they reach menopause; this seems to reduce their susceptibility pre-menopause to hypertension, increased LDL-cholesterol and type 2 diabetes than men [21]. On the other hand, visceral fat is associated with fat deposition in the middle of the body. In a study [22], the level of active testosterone and to a smaller extent, estradiol (the main form of estrogen) in women seemed to be linked to the level of visceral fat in the body as evidenced by CT scans. The same study also showed that a woman's age did not correlate significantly with the amount of visceral fat, nor did race or other cardiovascular factors. However, other studies seemed to show that age and race influence the tendency to obesity [23, 24].

Despite the negative connotations associated with adiposity, adipocytes (fat cells) are vital to human health as much as the heart, kidneys and liver are. Adipose tissue exerts important endocrine and immune functions through the release of adipokines, which regulate adipose tissue metabolism and are associated with alterations in insulin resistance [25]. It seems that both overall and central obesity are significantly associated with irregular menstrual cycle events and this appears to be mediated by hormonal factors particularly testosterone, sex hormone binding globulin and insulin [26]. Age, the change in the location of fat deposits, the size and total amount of adipocytes may explain the change in the shape of women after menopause. During this phase of life, estrogen, the hormone that governs the female monthly cycle diminishes, leading to fat migration from the hips, arms and thighs to the abdomen, and is hypothesized to lead to higher susceptibility of post-menopausal women to cardiovascular disease and type 2 diabetes than their younger counterparts [27]. Also, enlarged sub-cutaneous abdominal adipocytes have been shown to predict the 


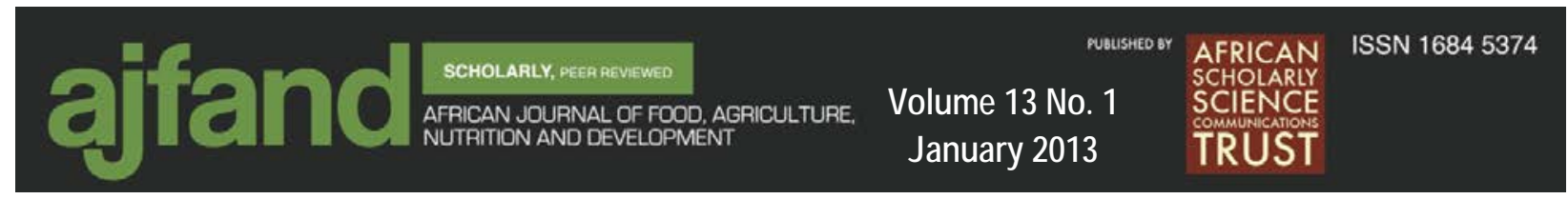

incidence of type 2 diabetes in women, in later life [28]. Post-menopause, progesterone production diminishes in addition to estrogen decline, leading to the need for the body to produce more of both hormones; this occurs by the deposition of more fat cells in the thighs, hips and breasts. The decline in progesterone level leads to the retention of greater amount of body fluid, which is manifest as weight gain. Fat is therefore at the centre of a very complex system which coordinates several body functions, but whose excess deposition can impair human health.

Generally, obesity is associated with over-nutrition, low physical activity, change of dietary habits, urbanization, modernization, the socioeconomic class and in a minority of patients to a physical condition or metabolic disturbance [15]. High calorie intake, high consumption of fatty meats and oily foods, and high alcohol consumption combined with low physical activity are likely to lead to obesity. Habitual, high alcohol consumption and other habitual indulgences contributing energy in excess of physiological requirements may result in visceral fat deposition. The change of leisure activities to those that require low energy expenditure may also lead to adiposity and therefore potential obesity. Aging results in slowing metabolism and reduced physical activity, resulting in weight gain, which if not watched predisposes to obesity [21].

\section{Other factors influencing obesity}

Generally, eating to the extent inappropriate with one's physical activity seems to be the direct cause of obesity. Obesity is thus a behavioural disorder that is classifiable as a psychiatric disorder [21]. Cultural factors also seem to influence the tendency to obesity [29]. In a social study in South Africa, moderate obesity in African women made them admirable to the menfolk [30], while the Sumo wrestler in Japan requires some degree of overweight, not all being muscle.

Adolescents tend to eat more than adults, while boys may eat more than girls. Individuality also affects food intake and therefore the tendency to adiposity and potential obesity. Many other seemingly unconventional factors are currently being considered as contributing to obesity. These include "sleep debt" (sleeping less than one should), pollution due to the many chemicals in the environment, which can affect hormonal balance and may influence obesity, as hormones control body weight [31]. Normally, being in a hot or very cold environment encourages the burning of calories. However, being in an air conditioned environment reduces calorie utilization. Many drugs including contraceptives, steroid hormones, diabetes drugs, some antidepressants and blood pressure drugs may cause undue weight gain. It is also emerging that giving birth when older, may carry the risk of the child being obese [31]. Marriage of obese couples may lead to obesity in the next generation [31].

\section{Genetic defects, endocrine factors, trauma and obesity}

In man, obesity seems to run in families, but it may be difficult to separate genetic from environmental factors [32]. There are rare genetic disorders such as Prader-Willi Syndrome in which obesity is a clinical feature. This syndrome is characterized by muscle hypotonia, mental retardation, diabetes and obesity [33]. Obesity frequently accompanies hypothyroidism, hypogonadism, hypopituitarism and Cushing's syndrome, although it is not an essential feature of these conditions [21]. The fact that 


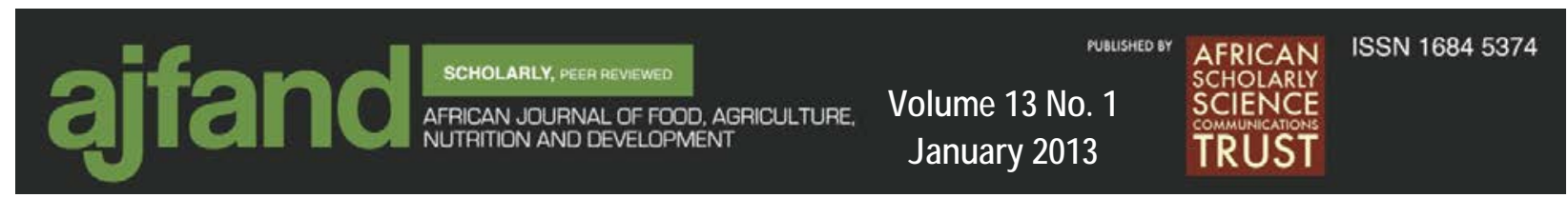

in women obesity commonly begins at puberty, during pregnancy or at menopause suggests an endocrine link. Yet the overwhelming majority of obese patients show no clinical evidence of an endocrine disorder and the function of their endocrine glands may be normal on routine testing. Newer tests may show yet undiscovered, small, but probably important deviations in endocrine or metabolic functions that may lead to obesity. Although generally uncommon, obesity may follow damage to the hypothalamus and its connections after a head injury or other localized lesion. It has been reported that lesions of the ventromedial nucleus of the hypothalamus induce increased food intake, an action that may lead to obesity where other contributing factors exist [34].

\section{EFFECTS OF OBESITY ON HUMAN HEALTH}

Obesity is a multifactorial disease. It occurs at all ages and commonly affects the health of infants, adolescents and the elderly. Even being overweight seems to predispose one to type 2 diabetes, hypertension, stroke, heart attack, congestive heart failure and several cancers (mainly colorectal and prostate) [35]. Most obese patients are observed to have decreased glucose tolerance, decreased sensitivity to insulin, decreased production of ketone bodies during starvation, and decreased sensitivity to growth hormones, while showing increased plasma insulin, plasma free fatty acids, plasma triglycerides, plasma cholesterol, plasma uric acid, and urinary 17hydroxycorticoids $[36,37]$. These metabolic changes are probably a result of obesity and not its cause. Obesity is associated with macrophage infiltration and with both hyperplasia and hypertrophy of adipocytes, which often leads to the chronic diseaseprone state of such patients [38]. However, the most significant metabolic changes related to obesity are decreased glucose tolerance, decreased sensitivity to insulin and increased plasma insulin [37, 39]. Hyperinsulinaemia is thus an important change that is probably due to inadequate feedback inhibition of insulin secretion or reduced numbers of insulin receptors associated with obesity [39]. Many obese people may therefore be in a pre-diabetic state. Other obesity-associated observations include reduced life expectancy and strenuous exercise intolerance [40]. Exercise intolerance is evident as shortness of breath on exertion and fatigue on continuing physical activity. This may be due to the burden of the increased weight and a reduced capacity of the circulatory and respiratory systems that work under handicaps imposed by the masses of internal fat and fat infiltration of muscle. These latter observations are found in class II and III obesity. Such patients are at risk of a number of metabolic disorders including diabetes, hypertension, gall bladder diseases, fatty liver, gout, pulmonary disorders, osteoarthritis, hernias (diaphragmatic and abdominal), varicose veins and intertriginous dermatitis [36, 21]. Mortality rates increase with increasing weight and life expectancy may be reduced [41, 42]. When operated upon, obese patients are under increased risk of death when under anesthesia; surgical operations on them are difficult and are often accompanied by post-operative complications [41]. Daily activities of Class III obese patients are severely restricted by their enormous mass; they are also likely to suffer from serious psychological disturbances [21]. This may justify the application of cognitive-psychological therapies for their treatments and management, among others.

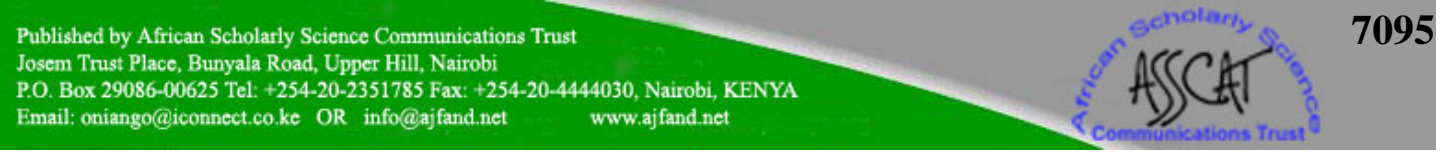




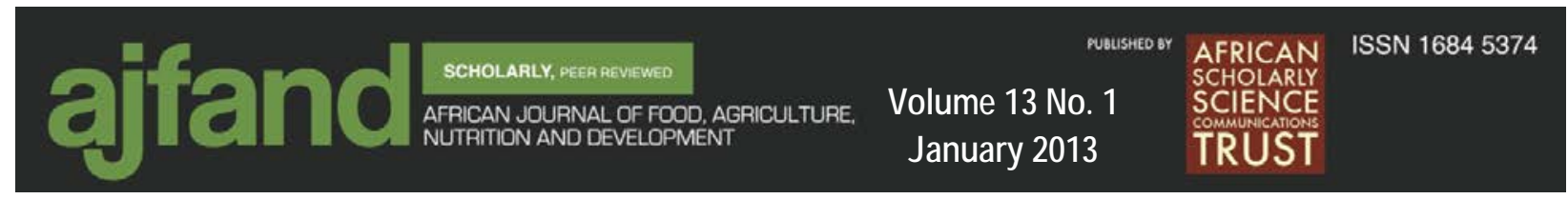

\section{CONTROL AND TREATMENTS OF OBESITY}

Treatment of the disease is simple in principle. If a patient eats a diet that provides 500-1000 Kcal (1-4 MJ) less than is needed for the activities of daily life, then and only then will the excess reserves of energy in adipose tissue be drawn upon and weight lost at a rate of $0.5-1 \mathrm{~kg}$ each week [21]. However, in practice, this is difficult for most patients, since it requires changes in long established habits with a new discipline, similar to that which an athlete imposes on herself when going into training.

\section{Physical exercise and dietary advice}

Besides restricting food intake, physical fitness should be improved by engaging in as much exercise as possible in order to lose weight, but also to maintain the appropriate weight in the long-term [43]. Exercise may prove difficult for many patients in the early phase of rigorous exercises they may not be accustomed to. Only with strong motivation maintained over long periods can patients lose weight and sustain the loss. Doctors, dieticians and mutual exchanges in slimming clubs can provide the support for morale. Although exercise can help reach a target weight, dietary restriction and control are more effective as part of treatment of obesity [43]. Obese patients are advised to walk, when possible, rather than use their cars or public transport, to climb stairs rather than use the elevator and to take up one or more hobbies demanding physical exercise. Hobbies that are suitable for the middle aged and elderly demanding physical exertion include dancing, swimming, jogging, golf and gardening. Even if exercise contributes only little to a negative energy balance, it benefits by promoting physical fitness, and preventing muscle atrophy. Insufficient use of the muscles of the trunk and limbs of the respiratory system and of the myocardium increases the risk of orthopaedic, respiratory and circulatory disorders [21]. In women, planned loss of weight after menopause seems to reduce the risk of breast cancer [44]. Patients also require practical advice on food and health based on hard science, and, not on false ideas of no practical value which often circulate widely, and can be taken readily by despairing patients. It is advisable to set a target weight and a realistic time to reach this target. This should be agreed upon between the patient and the adviser at the start of treatment. Once the target has been fixed, progress should be monitored and checked regularly by weighing and BMI calculation [21]. Dietary advice has to be tailored to the patient's previous food history which should be obtained in as much detail as possible. Due to their high energy density, it is advisable to remove from diets such high calorie items as refined sugar, sweets, candies, jams, jellies, honey, syrups, canned or frozen fruits (unless preserved without sugar), dried fruits, cakes, ice cream, fatty meats, sausages, fatty fish, fried foods, mayonnaise and salad dressings, cream sauces, carbonated beverages, beers, spirits and all alcoholic beverages generally [45]. It is also reasonable not to miss any normal meal in the patients' dietary history to avoid oversnacking with "junk" foods between meals. However, there is a possibility that any curtailment of food intake can reduce the intake of essential nutrients. To avoid such eventualities, all food regimes should include ample fruit and vegetable helpings to supply vitamins, minerals and dietary fibre [21]. Their ample inclusion also promotes satiety and satisfaction on eating. Where anaemia develops, due to iron deficiency, 


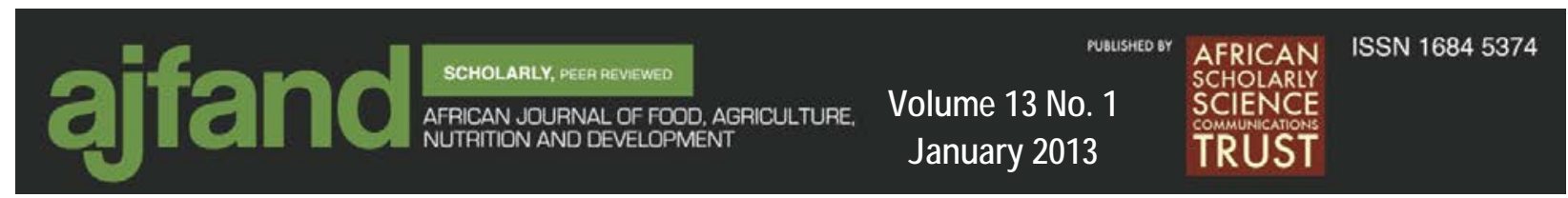

haemoglobin or an iron supplement should be provided. It is important that patients do not reduce their dietary energy below $1000 \mathrm{kcal} /$ day except on medical advice and with close supervision [45]. If dietary intake is below $1000 \mathrm{kcal} /$ day, excessive losses of potassium and nitrogen may occur and patient urinary outputs should therefore be checked regularly [21]. During therapeutic total starvation, the urinary nitrogen excretion can be reduced from the usual level of 6-8 g/day by giving DL-3hydroxybutyrate (18 g/day) and this was observed to be more effective in sparing protein than a similar dose of glucose [46]. The administration of the drug did not affect weight loss, but seemed to increase the fat/lean ratio of the tissue lost [46]. Diets providing $\leq 500 \mathrm{kcal} /$ day or a period of total starvation may be justifiable in some patients (Class III obese) who are not responding well to less rigorous restrictions [21]. However, close medical supervision is necessary. Only with selected patients with no orthopaedic or cardiovascular complications is it possible to increase physical activities [21].

\section{Tested and potential drugs for treating obesity}

Amphetamine and its derivatives have been used as "slimming agents". They are psychomotor stimulants and have an anorectic action. They may aid patients adhere to their diets, but it is not justifiable to use them at the start of treatment [21]. By stimulating higher cortical centres, they may overcome feelings of fatigue, depression, and create a sense of well being. However, they may cause insomnia, increase heart rate, raise blood pressure and severe psychotic reactions, besides creating dependency in a majority of patients $[47,21]$. Serious withdrawal symptoms occur on discontinuing the drug and therefore amphetamine should not be prescribed for obese patients. Generally, anorectic drugs should never be a substitute for a dietary regime and radical alteration of food habits. Thyroxine stimulates metabolism and therefore has had extensive trials in the treatment of obesity. However, because it is contraindicated, except in those cases where obesity is associated with evidence of hyperthyroidism, it is not recommended for obesity treatment [21]. Its administration is not only dangerous for euthyroid elderly patients with myocardial weakness, but also useless as it does not increase metabolism unless applied in large doses that cause tremor, diarrhoea, palpitation and tachycardia [47]. Sedatives and tranquilizers may only be useful for obese patients who suffer from an anxiety state [47, 48]. Diuretics are potentially dangerous, but may be useful where the patient has oedema arising from cardiac failure or other organic disease [48]. Other drugs and materials which though available (often by non-subscription) for obesity treatment are not effective include ephedrine, chitosan, St. John's wort, hydroxycitric acid, herbal laxatives and diuretics, appetite depressants, and 5-hydroxytryptophan [3].

\section{Surgical treatment of obesity}

Surgical interference with the gastrointestinal tract aiming at reducing food intake, may be considered in patients in whom medical treatment as discussed in earlier chapters has failed, and whose life has been made miserable by severe obesity. Various forms of jejunoileostomy which by creating a bypass of the small intestine, lead to malabsorption, have been tried [21]. Food intake has often to be reduced to prevent flatulence, diarrhoea and abdominal discomfort [21]. The operation seems unphysiological and carries a mortality rate of about 4\% [21]. Due to complications 


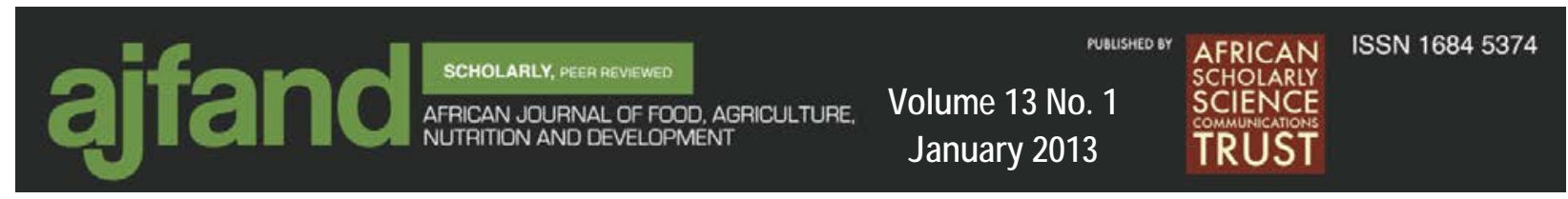

related to malabsorption and the blind loop syndrome, such operations are seldom carried out. An alternative approach is to reduce the size of the stomach, potentially forcing the patient to reduce food intake. Gastroplasty is an operation in which the stomach is reduced to a small reservoir, about $60 \mathrm{~mL}$ in capacity, in the fundus, which drains through a narrow channel, about $12 \mathrm{~mm}$ in diameter, a long the greater curvature and into the duodenum [49]. Although the weight loss was not much different from that of controls, those who had vertical banded gastroplasty (VBG) were able to maintain their weight loss better and for longer than gastric bypass operation [50]. Operations to reduce the size of the stomach seem safer and less unphysiological than those that restrict access of food to the small intestine. This is more so for the vertical banded gastroplasty-Roux -en-Y gastric bypass (VBG-RGB) technique, which is a preferred operation in weight loss surgery [50]. The application of adjustable gastric bands seems more humane and physiologically tolerable than the practically irreversible resection and by-pass operations [51]. Wiring the jaws with a dental splint is another procedure that is aimed at reducing food intake [21]. The patient can drink and speak, but not eat. Food intake is limited to liquid foods of low energy density. However, when the jaws are unwired, patients return to former eating habits and regain weight [21]. Removal of masses of fat from the stomach, thighs and arms is contraindicated; the appearance of irregular and ugly lumps of fat at the operation sites has been observed [21]. Based on lessons learnt from operations with lesions made in the hypothalamus of rats, with the aim of producing aphagia, neurosurgeons aim to induce aphagia in humans with the hope that the problem of intractable obesity can be explored using stereotatic techniques [52]. Other procedures include laparoscopic metabolic surgery and bio-enteric intragastric balloon implantation [53]. These techniques may be favored because they are simple to use and are less invasive.

\section{SOME POTENTIAL AREAS FOR RESEARCH}

A number of potential research areas in connection with obesity include:

1. Finding better and more accurate methods and procedures and/or improving the accuracy of current methods of estimating obesity in individuals

2. Finding more accurate methods of estimating fat percentage in individuals

3. Accurately distinguishing overweight due to excess fat deposition and that due to muscle atrophy

4. Finding methods of surgery that are less invasive, are simple to use and result in less post-operative complications

5. Helping patients to re-socialize and improve the quality of life especially after surgery using various psycho-social and cognitive therapies

6. Working on effective pharmacotherapy-based reduction of post-operative complications

7. Finding drugs that have less side effects than those currently used especially in the management of post-operative complications 


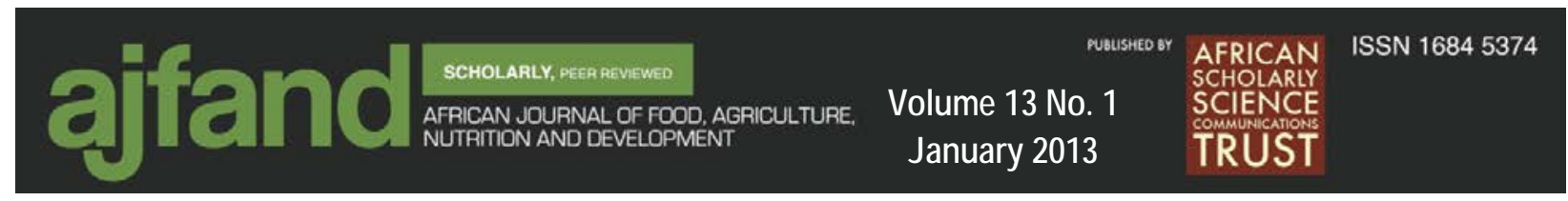

8. To confirm the potential link between foetal malnutrition or under-nutrition and predisposition to obesity in adulthood

9. Working on the potential use of blood hormonal levels for estimating obesity in individuals

\section{CONCLUSIONS}

Obesity results from over-nutrition, low physical activity, change of dietary habits, urbanization, and in a minority of patients to a physical condition or metabolic disturbance. To treat obesity, restricting food intake and engaging in physical fitness are necessary. Although exercise can help a patient reach a target weight, dietary restriction and control may be more effective for the treatment of obesity. Several forms of surgical procedures can be used where exercise and food restriction have failed, especially in morbid obesity. However, surgeries may be more expensive and carry with them certain uncertainties and problems than dietary plans combined with regular physical activity. It seems that society needs to instill in young people healthy and orderly eating habits based on sound nutritional science and to provide sports fields and the opportunities, education, encouragement and the motivation to use them on a regular basis. Exercise and sensible eating are the best ways to regulate body fat percentage [54]. Nevertheless, the key to keeping a healthy body weight is largely dependent on one's lifestyle. Despite lower rates of obesity than many regions of the world, obesity is increasing in Africa with rates in South Africa and North Africa being comparable to those in developed countries. African countries should therefore place measures in place to forestall its effects on health and burden on the health care system.

\section{RECOMMENDATIONS}

Although obesity may run in families, the key to maintaining a healthy body weight is sensible eating based on sound nutritional science and an active lifestyle. As it is difficult to treat obesity, efforts should be directed towards prevention. 


\section{REFERENCES}

1. CDC. Prevalence of obesity (class I, II and III) among adults aged $\geq 20$ years, by age group, and sex. National Health and Nutrition Examination Survey (US, 2007-2008), 2010. Found at http://www.cdc.gov/mmwr/preview/mmwr.html/mm5917a9.htm. Accessed on $30^{\text {th }}$ May, 2012.

2. Seidell $\mathbf{J}$ Assessing obesity: classification and epidemiology. Br. Med. Bull. 1997: 238-252.

3. WHO. Estimates of obesity. Found at www.who.int/mediacentre/statsheets/fs311/en/. Obesity and overweight Fact Sheet No. 33 of May 2012. Accessed on 11 $1^{\text {th }}$ June 2012.

4. Shah NR and ER Braverman Measuring adiposity in patients: the utility of BMI, percent body fat \& leptin. PLos ONE Journal 2012; 7(4): e33308.doi: 10371/pone.0033308. Accessed $11^{\text {th }}$ June 2012.

5. Rahman $\mathbf{M}$ and $\mathbf{A B}$ Berenson Accuracy of current body mass index classification of white, black and hispanic reproductive-age women. Obstet. Gynecol. 2010; 115(5): 982-988.

6. Yoshizumi T, Nakamuwa $\mathbf{T}$, Yamane $\mathbf{T}$, Arai $\mathbf{T}$ and $\mathbf{Y}$ Matsusawa Abdominal fat standardized technique for measurement at CT. Radiology 1999; 211: 283-288.

7. Barker D, Koparal S, Isik S, Pasaoglu L, Aydin Y, Erol K, Delibasi T and S Guler Compatibility of different methods of the measurement of visceral fat in different body mass strata. Dingn Intern. Radiol. 2010; 16(2): 99-105.

8. Yu O-K, Rhee Y-K, Park T-S and Y-S Cha Comparison of obesity measurements in overweight of elementary students using anthropometry, BIS (bioimpedance analysis), CT (computed tomography) and DEXA (dual-energy X-ray absorptiometry). Nutr Res Pract 2010; 4(2): 128-135.

9. WHO Global strategy on diet, physical activity and health, 2010. Found at: www.who.int/dietphiscalactivity/0publications/facts/obesity/en. Accessed on 29th August 2010.

10. Uauy R, Albala $\mathbf{C}$ and $\mathbf{J}$ Kain Obesity trends in Latin America: transition from under-to overweight. J. Nutr. 2001; 131(3): 893S-899S.

11. Kain J, Vio F and $\mathbf{C}$ Albala Obesity trends and determinant factors in Latin America. Cad Saude Publica 2003; 19 suppl 1: S77-86S. 


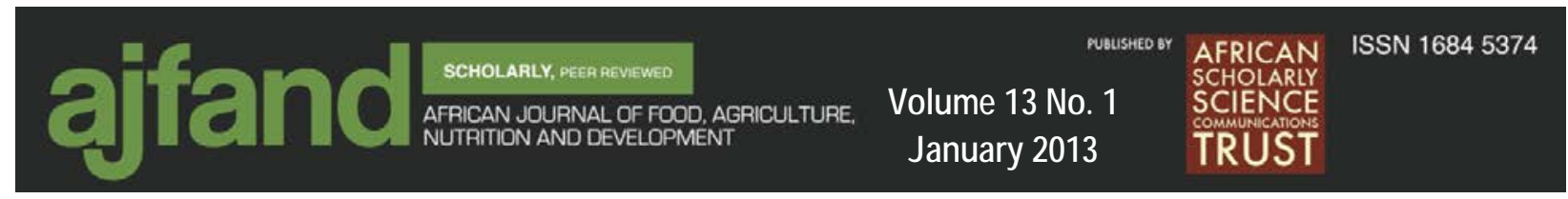

12. Jahns L, Baturin A and BM Popkin Obesity, diet and poverty: trends in the Russian transition to market economy. Eur. J. Clin. Nutr. 2003; 57: 12951302.

13. Food Standards Agency (UK) Obesity rates worldwide. Found at: http// www.food.gov.uk. Accessed on $29^{\text {th }}$ August, 2010.

14. WHO. Obesity in the United States of America. Report BCP 2005. Found at http://www.who.int/ncd surveillance/infobase/web/infobasecommon.pdf. 2005. Accessed on $28^{\text {th }}$ August 2010.

15. (Obesity Task Force), WHO. Global strategy on diet, physical activity and health: Obesity and overweight, 2005. Found at http://www.who/int/hpr/NPH/docs/gs_obesity.pdf. Accessed on $28^{\text {th }}$ August, 2010.

16. Goededcke JH, Courtney LJ and EV Lambert Chronic diseases of lifestyle in S. Africa, 1995-2005. Department of Biology, Faculty of Health Sciences, University of Cape Town, Cape Town, South Africa, 2005. Found at http://www.mrc.ac.ca/chronic/cdlchapter7.pdf. Accessed on 28th August, 2010.

17. Christensen AL, Hansen AW, Larsson MW, Mwangi DL, Kilonzo T, Boit MK, Kaduka L, Borch-Johnsen $\mathbf{K}$ and $\mathbf{H}$ Friis Obesity and regional fat distribution in Kenyan populations: Impact of ethnicity and urbanization. Ann. Hum. Biol. 2008; 35(2): 232-49.

18. US Census Bureau Extrapolation of prevalence rates of obesity to countries and regions. Found at http://www.wrongdiagnosis.com/o/obesity/statscountry.htm. Accessed on 30th November 2010.

19. Luke A, Dugas LR, Ebersole K, Durazo-Arvisu RA, Chao G, Scholler DA, Adeyemo A, Brieger WR and RS Cooper Energy expenditure does not predict weight change in either Nigerian or African American women. Am J. Clin. Nutr. 2009; 89(1): 169-176.

20. Zizza C, Siega-Riz AM and BM Popkin Significant increase in young adults snacking between 1978 and 1997, represent a case for concern. Prev. Med. 2001; 92: 303-310.

21. Passmore R and MA Eastwood Davidson and Passmore's Human Nutrition and Dietetics, $8^{\text {th }}$ Edition, Churchill Livingstone, Edinburgh, 1985.

22. Janssen I, Paul LH, Kazlanskaite R and SA Augusta Testosterone and visceral fat in midlife women: the Study of Women's Health Across the Nation (SWAN) fat patterning study. Obesity 2010; 18(3): 604-610. 


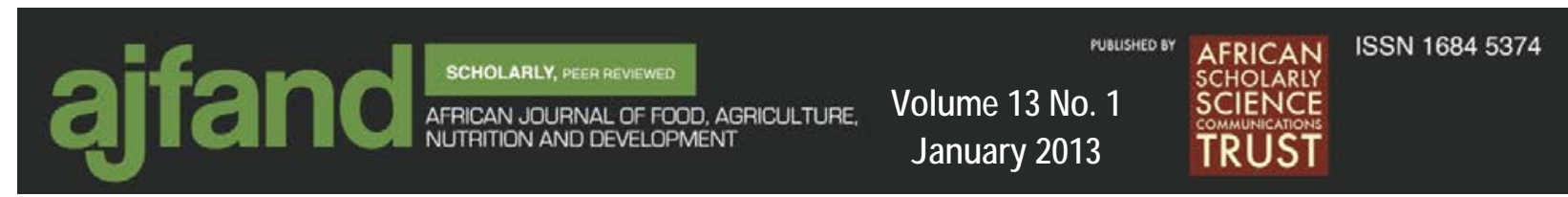

23. Novak CP Aging, total body potassium, fat-free mass, and cell mass in males and females between the ages of 18 and 85 years. J. Gerontol. 1972; 27: 43843.

24. Victor PG The Dallas Heart Study: A population based probability sample for the multidisciplinary study of ethnic differences in cardiovascular health. Am. J. Cardiol. 2004; 93: 1473-80.

25. Pittas CA and NA Joseph Adipocytokines and insulin resistance. J. Clin. Endocrinol Metab 2004; 89: 447-52.

26. Wei S, Schmidt MD, Dwyer T, Norman JR and AJ Venn Obesity and menstrual irregularity: association with SHBG, testosterone and insulin. Obesity 2009; 17(5): 1070-76.

27. Ridker OM, Manson JE, Baring JE, Shih J, Matias $\mathbf{M}$ and $\mathbf{C H}$ Hennekens Homocysteine and the risk of cardiovascular disease among postmenopausal women. JAMA 1999; 281(19): 1817-21.

28. Lönn M, Mehlig K, Bengtsson $\mathbf{C}$ and $\mathbf{L}$ Lissner Adipocyte size predicts incidence of type 2 diabetes in women. The FASEB Journal 2010; 24: 326-31. Also found at doi: 1096/fj.09-133058.

29. Lee D Cultural factors in dietary choice. Am. J. Clin. Nutr. 1957; 5: 166.

30. Pouane T, Fourie $\mathbf{J}$ and $\mathbf{M}$ Shapiro "Big is Beautiful"-an exploration of urban black women in a South African township. S. Afr. J. Clin. Nutr. 2005; 18: 6-15.

31. CDC. Causes of obesity. US Centers for Disease Control, 2001. Found at: http://www.cdc.gov.htm. Accessed on 10 ${ }^{\text {th }}$ September, 2010.

32. Price RA and Gottesman Jr. Body fat in identical twins reared apart: roles of genes and environment. Behav Genet 1991; 21: 1-7.

33. Cassidy SB and DJ Driscoll Prader-Willi Syndrome (PWS). Eur. J. Human Genetics 2009; 17: 3-13.

34. Anand BK and JR Brobeck Hypothalamic control of food intake in rats and cats. Yale J. Biol. Med. 1963; 24: 123.

35. Hossain P, Kawar B and M El Nahas Obesity and diabetes in the developing world- a growing challenge. $N$ Engl J Med. 2007; 356: 213-215.

36. Kaplan NM The deadly quartet-upper body obesity, glucose intolerance, hypertriglyceridemia and hypertension. Arch Intern Med. 1989; 149: 1514-20.

37. Kopelman PG Obesity as a medical problem. Nature 2000; 404: 635-43. 


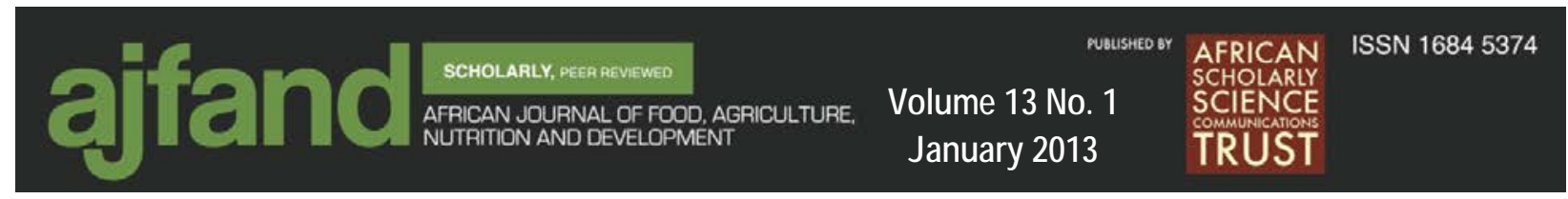

38. Wallen KE and GS Hotamisligil Obesity induced inflammatory changes in adipose tissue. J. Clin. Invest. 2003; 112: 1785-8.

39. Frayn KN and SW Coppack Insulin resistance, adipose tissue and coronary heart disease. Clin. Sci. (London) 1992; 82: 1-8.

40. Arnlöv $\mathbf{J}$, Ingelson $\mathbf{E}$, Sundström $\mathbf{J}$ and $\mathbf{L}$ Lind Impact of body mass index and the metabolic syndrome on the risk of cardiovascular disease and death in middle aged men. Circulation 2010; 121: 230-36.

41. Garrow JS Treat obesity seriously. Churchill Livingstone, Edinburgh, 1981.

42. Calle EE, Thun MJ, Petrelli JM, Rodriguez E and CE Heath Jr Body mass index and mortality in a prospective cohort of US adults. N. Engl. J. Med. 1999; 341(15): 1097-1105.

43. Maclean PS, Higgins JA, Wyatt HR, Melanson KJ, Johnson GC, Jackman MR, Giles ED, Brown IE and JO Hill Regular exercise attenuates the metabolic drive to regain body weight after long-term weight loss. Am. J. Physiol. 2009; 297: R793-R802.

44. Van den Brandt PA, Spiegelman D, Yaun S-S, Adami H-O, Beeson L, Folsom AR, Fraser G, Goldbohm RA, Graham S, Kushi L, Marshall JR, Miller AB, Rohan T, Smith-Warner SA, Speizer FE, Willett WC, Wolk A and DJ Hunter Pooled analysis of prospective cohort studies on height, weight, and breast cancer risk. Am J Epidemiol. 2000; 152: 514-27.

45. Melanson KJ Nutrition Review: Dietary considerations for obesity treatment. Am. J. Lifestyle Med. 2007; 1(6): 433-437.

46. Faulks RM, Li JB and AL Goldberg Effects of insulin, glucose and amino acids on protein turnover in rat diaphragm. J. Biol. Chem. 1975; 250(1): 29098.

47. Modell W Status and prospects of drugs for overeating. JAMA 1960; 173: 1131.

48. Fazekas JF Currents concepts in therapy: anorexigenic agents. $N$. Engl. $J$. Med. 1961; 264: 501.

49. Gomes CA Gastroplasty in morbid obesity. Surg. Clin. North Am. 1979; 59: 1113-20.

50. Capella JF The weight reduction operation of choice: vertical banded gastroplasty or gastric bypass? Am. J. Surg. 1996; 171(1): 74-79.

51. Bunde J, Csizar $\mathbf{M}$ and $\mathbf{M}$ Ursu Modern surgical interventions in the treatment of morbid obesity. Orv. Hetil. 2002; 144(50): 2459-63. 
52. D'Angelo PC, Galliano DE and AS Rosemurgy Stereotatic excisional breast biopsies utilizing the advanced breast biopsy instrumentation system. The Breast J. 1998; 4(2): 133.

53. Nikolic M, Bobar M, Ljubicic N, Supanc V, Mirosevic G, Nikolic BP, Galina B and M Bekavac-Beslin Position of intragastric balloons in global initiative for obesity treatment. Coll. Anthropol. 2011; 35(4): 1353-62.

54. Gidding SS Special article: Physical activity, physical fitness and cardiovascular risk factors in childhood. Am. J. Lifestyle Med. 2007; 1(6): 499505. 